\title{
CLIVAGENS RELIGIOSAS, GÊNERO E POLÍTICA NA ÍNDIA*
}

\author{
Zoya Hasan
}

\section{RESUMO}

Este artigo enfoca o impacto da política identitária em matéria de igualdade de gênero. Mais precisamente, ele explora o vínculo paradoxal entre religião e política numa sociedade multireligiosa, além da complexidade de uma situação em que se pretende que o ativismo das mulheres, tanto reforce quanto conteste a sua identidade sexual. Alguns dizem que a política religiosa nem sempre nega a igualdade de gênero. Veremos, no entanto, que a Índia oferece um exemplo notável de instrumentalização das mulheres em benefício de objetivos dos partidos políticos de direita. $\mathrm{O}$ artigo examina as estratégias dos mais influentes entre eles, bem como as linhas de ação de organizações de mulheres e de grupos de muçulmanos no que concerne à reforma jurídica e à controvertida e litigiosa questão de um Código Civil único. Contra a ideia de que a melhor maneira de ampliar os direitos das mulheres muçulmanas no contexto comunitário seria reformar o código do estatuto pessoal com base no feminismo islâmico, demonstraremos que tal abordagem tende a cristalizar as identidades em base a clivagens religiosas e que a política religiosa se utiliza dos direitos das minorias para marginalizar os direitos das mulheres.

Palavras-chave: Índia - religião - política identitária - direitos das mulheres - laicidade- nacionalismo hindu - movimento das mulheres.

\section{CLIVAGES RELIGIEUX, GENRE ET POLITIQUE EN INDE}

\section{RÉSUMÉ}

Cet article porte sur l'impact de la politique identitaire en matière d’égalité des sexes. Plus précisément, il explore le lien paradoxal

* Tradução da versão francesa para o português por Naira Pinheiro dos Santos. O texto original em francês, "Clivages religieux, genre et politique en Inde", Cahiers du Genre, 2012/3 (HS n 3), p. 69-87, foi traduzido do inglês por Jacqueline Heinen. 
entre religion et politique dans une société multireligieuse, outre la complexité d'une situation voulant que le militantisme des femmes, à la fois conforte et conteste leur identité sexuelle. D'aucuns affirment que la politique religieuse ne nie pas toujours l'égalité des sexes. On verra pourtant que l'Inde offre un exemple frappant d'instrumentalisation des femmes au profit des objectifs des partis politiques de droite. L'article examine les stratégies des plus influents d'entre eux, ainsi que la ligne de conduite des organisations de femmes et des groupes de musulmanes concernant la réforme juridique et la question litigieuse d'un Code civil unique. Contre l'idée que la meilleure façon d'étendre les droits des musulmanes dans le contexte communautaire actuel serait de réformer le code du statut personnel en s'appuyant sur le féminisme islamique, on montrera qu'une telle approche tend à figer les identités en fonction des clivages religieux et que la politique religieuse se sert des droits des minorités pour marginaliser les droits des femmes.

Mots-clés : Indie. Religion. Politique Identitaire. Droits des Femmes. Laïcité. Nationalisme Hindou. Mouvement des Femmes.

Os contornos econômicos e políticos da democracia indiana sofreram mudanças significativas que remontam aos anos de 1989-1991, marcados pela reestruturação neoliberal da economia e pelo rápido crescimento de organizações políticas adeptas do hinduísmo (Hindutva) - ideologia focada na supremacia hindu e segundo a qual a Índia (Hindustão) equivale a uma nação hindu (Maharashtra). A emergência do Partido Bharatiya Janata (BJP)' - principal partido de direita e líder do governo da coalizão denominada Aliança Democrática Nacional (NDA) no final dos anos de 1990 - marcou uma virada decisiva na política indiana contemporânea. Pela primeira vez, o BJP, porta-voz de um grupo de organizações militantes hindus (conhecido como Sangh Parivar), formava um governo a nível nacional, pondo fim assim a décadas de isolamento político. Contudo, quer se trate do pogrom² antimuçulmano em Gujarate em 2002 ou do comunitarismo introduzido como política em várias áreas (segurança, educação ou questões de gênero), a herança

N.T.: Partido do Povo Indiano.

N.T.: Perseguição ou atos em massa, espontâneos ou deliberados, de perseguição ou violência dirigida a um grupo étnico ou religioso, com a aprovação ou tolerância de autoridades locais. 
do BJP é no mínimo inquietante. A vitória da UPA (United Progressive Alliance $^{3}$ ) liderada pelo Congresso Nacional Indiano, que derrotou a coalizão liderada pelo BJP nas eleições de 2004 e de 2009 foi, por isso, vista como uma trégua pela política laica.

Afora os seis anos de governo de coalizão liderado pelo BJP em Delhi, a Índia nunca foi governada por um grupo que fizesse apelo explícito à religião. No entanto, a dimensão política e identitária da religião, embora mais sensível sob o governo do BJP, não pode ser imputada exclusivamente a este, porque constitui uma característica importante da vida pública. Mesmo um grupo laico como o Partido do Congresso, que governou a Índia por mais de quatro décadas, não resistiu ao apelo de vitórias eleitorais fáceis graças a concessões quanto ao caráter laico dos princípios e das instituições. Os partidos que procuram aparecer como pró-hindus, ou simultaneamente como pró-hindus e protetores das minorias, serviram de trampolim para a politização da religião.

A política identitária há muito tempo faz parte da paisagem política da Índia. Ela diz respeito a movimentos, a campanhas e a estratégias de mobilização partidária, bem como aos discursos de grupos que se apoiam em suas identidades de casta e sobre identidades religiosas para mobilizar seus adeptos e para aceder ao poder político e a bens públicos, quer se trate de serviços ou de recursos do Estado. Esses discursos tiveram um efeito tal nos debates sobre a "questão das mulheres" que a própria coerência da categoria «mulheres` passou a ser seriamente questionada. Examinaremos a seguir as conseqüências da interação entre política e religião para os direitos das mulheres - os das mulheres de grupos minoritários em especial - assim como para a democracia e para a laicidade na Índia, indicando de que maneira a perspectiva instrumental da política religiosa contribuiu para marginalizar a questão dos direitos das mulheres.

\section{LAICIDADE POLÍTICA}

A laicidade, na Índia como em outros lugares, implica na separação entre religião e poder político. As ponderações na origem desta

3 N.T.: Aliança Progressista Unida, coalizão de partidos políticos de centro-esquerda, sendo o principal deles o Congresso Nacional Indiano. 
separação não são, no entanto, exatamente as mesmas que na Europa Ocidental ou nos Estados Unidos. Foi preciso aguardar até 1976 para que a noção de laicidade figurasse na Constituição indiana. No entanto, e apesar de sérias divergências de interpretação, ela esteve no coração do projeto indiano de modernidade e de democracia, ainda que a Constituição não exija uma separação estrita e que a religião não seja efetivamente separada do Estado.

Diferentemente do modelo ocidental, o Estado optou por interpretar a laicidade como o dever de assegurar a proteção e a igualdade de todas as religiões, e de implementar uma regulamentação e uma reforma que fosse nesse sentido (Bhargava, 2007). Ao contrário da concepção americana, frequentemente percebida como estando baseada numa "barreira impermeável" entre as duas instituições, o estado indiano é autorizado a legislar contra preconceitos de disparidades e de casta que são tidos por legítimos na sociedade hindu, inclusive sobre questões como a entrada no templo dos anciãos intocáveis, a abolição do casamento de crianças e a erradicação de tudo o que está relacionado ao sistema dos intocáveis.

No geral, a laicidade foi adaptada ao contexto indiano para atender a exigências de governança, integrando os ideais religiosos de Gandhi e as ideias modernistas de Jawaharlal Nehru. A despeito de suas muitas fraquezas, essa estratégia funcionou por várias décadas. Mesmo face às pressões da direita hindu, Nehru nunca permitiu que a religião desempenhasse um papel político que colocasse em risco a unidade nacional.

Uma questão decisiva para a relação entre política e religião na Índia diz respeito aos direitos das minorias. Saber se estes deveriam receber tratamento especial da parte do Estado continua a ser objeto de sérias controvérsias, especialmente no período recente: os ataques sistemáticos da direita hindu aos direitos das minorias levaram ao questionamento do vínculo entre estes e a laicidade (Bhargava, 2003) - ataques tanto mais virulentos "à medida que a laicidade implicasse conceder uma igualdade real às minorias religiosas" (Needham, Sunder, 2007, p. 2).

A questão dos direitos das mulheres se insere na mesma ordem de problemas. De fato, um dos principais fundamentos da laicidade re- 
sidia na sua promessa de igualdade de gênero e de apoio às mulheres. A igualdade perante a lei constitui uma premissa nesse sentido, como explicitamente enunciado nos artigos $14^{\circ}$ e $15^{\circ}$ da Constituição indiana. Um dos principais desafios em matéria de igualdade de gênero diz respeito ao código do estatuto pessoal ${ }^{4}$, cuja reforma se impôs logo após a independência para atender às exigências de laicização e de modernização, e para lhe conferir um caráter justo, equitativo e não discriminatório. Os dirigentes da Índia moderna pós-colonial manifestaram sua disposição de intervir nas questões do estatuto pessoal, geralmente consideradas como sendo da alçada das autoridades religiosas e tradicionais, e ainda sujeitos aos preceitos religiosos e consuetudinários (os quais frequentemente concedem menos direitos às mulheres do que aos homens). No entanto, apenas o código hindu foi afetado pela reforma (Chatterjee, 1998).

No ano seguinte à independência, o governo de Congresso, sob a direção de Nehru, adotou certo número de leis progressistas relativas, entre outras, ao casamento e ao divórcio (1955), à adoção e manutenção da família (1956), a menores e à tutela (1956), bem como à sucessão e à herança (1956). Tantas mudanças rompendo com a tradição escritural e constituindo passos importantes com vista à liberalização e à laicização do código do estatuto pessoal hindu, por um lado, e à eventual adoção de um código civil único, por outro lado (Parashar, 1992). Nehru saudou essa reforma como revolucionária e como "a conquista mais notável do seu tempo" (Som, 1994). Essas mudanças iam suficientemente longe rumo à eqüidade de gênero, mas sem produzir uma igualdade completa. Anos depois, as organizações de mulheres teriam que invocar seu caráter insuficiente, uma vez que, na prática, as mulheres não têm os mesmos direitos e que, além do mais, a maior parte dessas leis são desrespeitadas impunemente. Por exemplo, a lei hindu sobre o casamento de 1955 autoriza uma menina a se casar aos dezoito anos, mas ao menino apenas com vinte e um anos de idade. Do mesmo modo, a

O código do estatuto pessoal muçulmano se refere ao direito da família que rege as relações domésticas entre os muçulmanos na Índia. Abrange questões como herança, casamento, divórcio, pensão alimentícia e adoção, consideradas como questões pessoais na medida em elas se referem à família ou à esfera privada. 
lei hindu sobre as sucessões prevê condições diferentes de acordo com o sexo dos/as herdeiros/as.

Ainda mais controversa do que as lacunas da reforma da lei hindu foi a relutância do Estado em adotar uma abordagem semelhante no que concerne aos códigos de estatuto pessoal das comunidades religiosas minoritárias (muçulmanos, cristãos, sikhs e pársis), para alinhá-las com as noções modernas de igualdade entre os sexos. As críticas se concentraram principalmente sobre o que foi percebido como um exercício desigual de poder do Estado, que impôs uma reforma das instituições e das práticas aos hindus, mas não para os muçulmanos indianos. Esse tratamento assimétrico era aberrante, até mesmo do ponto de vista da igualdade enquanto cidadãos/ãs: a partir do momento em que se admitia a intervenção do Estado para assegurar a igualdade de direitos dos membros de uma das comunidades, o que justificaria não fazer o mesmo em relação a outras?

Embora Nehru achasse vital - para o país como um todo, bem como para o desenvolvimento nacional - realizar uma reforma jurídica de todos os códigos de estatuto pessoal e adotar um único Código Civil (unificando, assim, os códigos das diversas comunidades religiosas na Índia), ele temia impor qualquer coisa para as minorias sem o seu consentimento, julgando que isso seria imprudente. Assim, a fusão de todos os estatutos em um único dispositivo legal foi adiada sine die, esperando que as comunidades minoritárias estivessem prontas para engajar-se em tal processo ou desejosas de contribuir para isso.

Os códigos de estatuto pessoal das minorias permaneceram, portanto, inalterados após a independência. Com algumas exceções, os líderes muçulmanos se opuseram firmemente à adoção de um código único, insistindo que essas leis são intrínsecas à sua religião e que, portanto, o Estado não deveria legislar sobre isso. E embora a maioria parlamentar fosse composta de hindus favoráveis à reforma desses códigos (Mehta, 2008), eles hesitaram em impor a vontade da maioria a uma minoria desfavorecida e sub-representada. 


\section{FORTALECIMENTO DA POLÍTICA IDENTITÁRIA: O PAPEL DO CON- GRESSO E DO BJP}

Desde a independência e durante mais de quatro décadas, o partido do Congresso desempenhou um papel chave na cena política indiana. Seu declínio teve início no final da década de 1960, fragilizando com isso o regime laico da Índia. Até então, o peso da religião na política havia sido limitado e os partidos comunitários haviam ganho apenas algumas cadeiras no Parlamento. Embora Indira Gandhi fosse muito apegada à dimensão laica do Estado indiano, a sua definição de laicidade baseava-se na igualdade de todas as religiões e não numa rejeição da religião ou numa total separação entre política e religião. A propensão a ultrapassar os limites das normas constitucionais em matéria de religião e laicidade abriu uma brecha para a rápida ascensão de uma alternativa antilaica. Uma série de eventos - imprevistos ou calculados, de acordo com o caso - facilitou a ingerência das forças antilaicas no sistema político. O desmantelamento do tecido laico começou com reivindicações de autonomia regional no Punjab e a forma como o Estado respondeu a essas exigências.

Num acórdão proferido em 1985, o Supremo Tribunal pediu a promulgação de um Código Civil único que daria a todas as mulheres direitos iguais, independentemente de sua religião - incluindo o direito à pensão alimentícia após o divórcio. A questão, neste caso específico, dizia respeito ao direito de uma muçulmana divorciada, Shah Bano, reivindicar uma pensão de seu ex-marido ao abrigo do Código de Processo Penal. Evitando a questão constitucional da igualdade, o Tribunal discutiu longamente a compatibilidade desse código com o Alcorão. Isso causou um grande tumulto político. A conselho do clero, o governo tomou a decisão de anular o veredito do tribunal e de promulgar, em 1986, a lei sobre proteção aos direitos das mulheres muçulmanas em questões de divórcio (MWA), que estabeleceu que elas não podem recorrer ao direito civil em caso de casamento e de divórcio. A nova lei criou problemas não somente em termos de igualdade de gênero, mas também quanto à não discriminação a qualquer que seja a religião: as mulheres muçulmanas eram as únicas a terem tal recurso recusado pelo código penal. Ela reforçou a ideologia dos nacionalistas hindus, que reprovaram 
ao Congresso o fato de ter acalmado os muçulmanos por esse viés, e privou Rajiv Ghandi do apoio de uma grande parte da comunidade hindu nas eleições de 1989, especialmente das classes médias (Hasan, 1998).

O fato mais marcante na sequência de eventos que enfraqueceram e desestabilizaram a laicidade foi a má gestão do conflito envolvendo a mesquita de Ayodhya. A partir de meados dos anos de 1980, o BJP e suas organizações afiliadas haviam lançado uma campanha nacional para construir um templo de Ram no local onde estava a mesquita Babri em Ayodhya, no estado de Uttar Pradesh, no norte da Índia. Os ativistas hindus afirmavam que a mesquita estava no lugar exato do suposto lugar de nascimento do Senhor Ram. Através de várias decisões no nível central e em Uttar Pradesh (abertura do local em litígio, possibilidade de colocar as pedras da fundação do futuro templo Ram perto da mesquita), o governo do partido do Congresso esperava reconciliar-se com as fileiras hindus para fins eleitorais, mas o resultado foi o comprometimento do princípio da separação entre religião e política e, sobretudo, o de incentivar o BJP a intensificar sua campanha em favor de um templo de Ram.

Tanto as decisões tomadas no caso de Shah Bano quanto no da mesquita de Ayodhya, destinadas a agradar os comunitaristas muçulmanos num caso e os comunitaristas hindus no outro, acabaram resultando num formidável impulso às forças da direita hindu, como evidenciado pela ascensão do BJP, que passou de somente duas cadeiras na Lok Sabha (câmara baixa do Parlamento) em 1984, para oitenta e nove cadeiras em 1989. Conceder uma coisa a uma comunidade para em seguida fazer o mesmo para com as outras comunidades, a título de compensação, só poderia aguçar o sentimento, tanto dos hindus quanto dos muçulmanos, de que eles eram perdedores.

Embora a presença de nacionalistas hindus remonte a quase um século, seu peso na vida pública da Índia afirmou-se somente a partir da década de 1980. O RSS (Rashtriya Swayamsevak Sangh, também conhecido como Sangh) é o coração de uma constelação de formações políticas incluindo o BJP, o VHP (Vishwa Hindu Parishad) e o Bajrang Dal. Juntos, eles pretendem instaurar um Estado hindu (Rashtra) com a ajuda de suas organizações afiliadas, minimizando as divisões entre os 
hindus através da integração de todas as castas, comunidades e seitas em um todo homogêneo. O sucesso desse projeto, no entanto, esbarra em uma série de dificuldades óbvias, já que nem todos os indianos são hindus. Além disso, a diversidade de hindus, divididos em muitas castas e subcastas, constitui um obstáculo ainda mais significativo. Para superá-lo, os nacionalistas hindus projetam a figura do muçulmano como a do "outro" - o inimigo contra o qual todos os hindus devem se unir. Os fundamentos de tal união não repousam, portanto, no que eles têm em comum, mas na sua oposição comum ao "inimigo interno".

$\mathrm{O}$ crescimento do nacionalismo hindu, especialmente no norte e no oeste da Índia, foi favorecido em grande medida pela oposição ao sistema de cotas de empregos nas áreas educacional e governamental para as castas baixas. A hostilidade das classes médias a tal princípio abriu rupturas entre as castas superiores e inferiores, identificadas repetidamente como intimamente ligadas às tensões comunitárias. Os conflitos entre as castas também assumiram, por vezes, contornos de violências comunitárias (Shani, 2007).

A estratégia usada em relação à mesquita de Ayodhya ilustra a lógica mais geral do agrupamento de partidos de direita, o Sangh Parivar, que confere um lugar central aos símbolos religiosos, mas cujos objetivos são mais políticos do que religiosos. O BJP, que ocupava o lugar de principal partido de oposição desde as eleições de 1990-91, viu-se pressionado pelos líderes do Sangh e do movimento, que o haviam impulsionado para o centro da cena política e que o incitavam agora a se concentrar na questão da mesquita. O VHP alimentava a mobilização organizando procissões de Ram em muitas regiões. Peregrinos hindus e militantes do Sangh continuavam a visitar o local e, em seis de dezembro de 1992, uma profusão de militantes de partidos de direita adentrou a área em litígio e demoliu a mesquita. Por um lado, esse ato permitiu ao BJP mostrar que era capaz de eliminar o que descrevera como um grande símbolo de vergonha, mas, por outro, privou-o de um tema favorável para a mobilização das massas. Esse período foi marcado também por ondas de tumultos comunitários, que produziram milhares de mortes no norte e no oeste da Índia e que resultaram na eleição do primeiro governo, no nível central, da Aliança Democrática Nacional (NDA), li- 
derado pelo BJP. Em 2002, o estado de Gujarate foi inundado por uma onda de violência comunitária contra os muçulmanos. De acordo com as estimativas, quase duas mil pessoas foram massacradas nessa ocasião. Gujarate é um exemplo notável dos erros terríveis que a política religiosa pode suscitar, quando um partido político se apoia numa ideologia baseada no nacionalismo religioso e na homogeneidade étnica, quando a violência é encorajada pelas mais altas esferas governamentais e não é tomada nenhuma medida contra os seus autores.

\section{INSTRUMENTALIZAÇÃO DAS MULHERES PELA DIREITA HINDU}

O movimento envolvendo a mesquita de Ayodhya, em 1990, foi uma oportunidade para o Sangh mobilizar as mulheres, com o apoio de suas organizações afiliadas, esforçando-se para promover suas dirigentes a posições e funções públicas e elegendo mulheres para as assembleias legislativas. Pela primeira vez, ele fez recrutas para a causa hindu nas camadas instruídas das classes médias e nas profissões liberais. Esse foi um grande avanço, pois ele conseguiu mobilizar as mulheres e conquistá-las para a política da direita hindu. A maioria delas não vinha de organizações ou de movimentos de mulheres e elas eram, portanto, indiferentes às reivindicações das mulheres. Suas atividades na esfera pública eram essencialmente uma réplica do seu papel na esfera privada (Sarkar, 1998) - elas se encarregavam principalmente de preparar mantimentos para os karsevaks (voluntários hindus) durante a campanha de Ayodhya.

A associação das mulheres hindus, no entanto, não se limitava a um papel de apoio ao movimento de Ayodhya. Muitas delas participaram ativamente da campanha pela demolição da mesquita de Babri, em dezembro de 1992, incitando seus companheiros a praticarem atos de violência contra os muçulmanos, ou até mesmo envolvendo-se diretamente nessas ações (BASU, 2001). Elas estavam muitas vezes à frente das procissões que percorriam bairros muçulmanos, brandindo trishuls (tridentes) e gritando slogans incendiários. Elas foram vistas orientando multidões hindus nessa direção e, pior ainda, impedindo que a polícia viesse em auxílio às famílias atacadas (Basu, 1998). Fica claro a partir desses episódios que a liderança da direita hindu não defende o pacifis- 
mo, mas incita as mulheres à violência sectária. Além disso, a ausência de qualquer sanção só poderia contribuir para esse fim, uma vez que os perpetradores das violências estão certos de que nunca serão punidos ou responsabilizados por seus atos.

Mas, por outro lado, o Sangh Parivar promove o ativismo das mulheres, o que valeu novos apoios para o BJP desde 1989. A adesão à Samiti Rashtriyasevika5 leva seus membros a fazer intervenções em público e, portanto, a sair do ambiente familiar. Os ideólogos do Hindutva têm orgulho das mulheres se manifestarem nas ruas para apoiar o movimento, reforçando a identidade comunitária através de uma religiosidade explícita e agressiva. Muitos dirigentes interpretam a participação das mulheres hindus na vida pública como um sinal de emancipação. Tanika Sarkar (1999) observa, no entanto, que embora o Sangh as tenha estimulado a se envolverem, ele o fez de uma maneira que não desafia fundamentalmente as suas atribuições tradicionais na esfera doméstica, o que constitui uma marca de conservadorismo. Ela observa também que ele apoiou a educação, o emprego e o ativismo das mulheres, mas apenas numa ótica de violência comunitária e de adesão a objetivos que implicam extrema disparidade social. A imagem pública das adeptas da Samiti reforçou as ideias conservadoras sobre as mulheres e seu estatuto. Elas consideram que o seu trabalho é diferente do de outras organizações que ensinam às mulheres quais são os seus direitos. De sua parte, ensinam-lhes a sacrificar-se para preservar a unidade da família, sendo boas mães; elas não fazem nada para ajudá-las a emancipar-se como mulheres. Em outras palavras, a ideologia da Samiti é "uma forma de capitulação perante o patriarcado" (Sarkar, 1999, p. 150), porque seu propósito primordial não é a defesa dos direitos das mulheres, mas a causa do RSS e a disseminação de suas idéias. Enquanto o movimento das mulheres questiona o princípio da subordinação das mulheres dentro da família e na sociedade, a ideologia do Hindutva Ihes atribui a esfera privada e defende um modelo patriarcal, ainda que favoreça seu acesso ao espaço público (Bedi, 2006).

N.T.: Organização de mulheres nacionalistas hindus que corresponde ao Rashtriya Swayamsevak Sangh para os homens. 
Como o objetivo central do BJP é tomar o poder, ele encoraja as mulheres a se envolverem na política e, sobretudo, a se candidatarem nas eleições. Ele coloca orgulhosamente em evidência aquelas que são eleitas para cargos legislativos ou executivos e posa de fervoroso defensor dos direitos das mulheres, às quais ele alega reservar um terço dos assentos no Parlamento. Conceder-Ihes postos é uma necessidade evidente, dada a sua presença crescente nas fileiras do partido, mas poucos foram os assentos efetivamente atribuídos às mulheres. A esse respeito, ainda que os resultados alcançados não tenham sido muito bons no geral, o partido do Congresso apresentou muito mais candidatas do que o BJP e a maioria das mulheres eleitas para o Parlamento vêm de suas fileiras (Basu, 2005).

Embora a promoção das mulheres não seja fundamental para o projeto do Hindutva, seus dirigentes parecem desejosos de apoiar os direitos das mulheres muçulmanas. Por um lado, o BJP denuncia o princípio dos direitos das minorias - elemento-chave da laicidade indiana - como um privilégio injustificado, com o que visa dissociar laicidade e direitos das minorias (Prakash, 2007). Por outro lado, apoia os direitos das mulheres muçulmanas, com a finalidade de chamar a atenção para a não reforma do código do estatuto pessoal muçulmano, o qual pretende que seja abolido. Esse apoio visa compensar seus ataques aos direitos das minorias e se apresentar como liberal, ainda que pouco contribua para promover os direitos das mulheres hindus.

\section{RELIGIÃO, OBJETIVOS FEMINISTAS E CÓDIGO CIVIL ÚNICO}

Ao longo dos anos, o debate sobre a religião no movimento de mulheres passou de uma postura de quase silêncio a esforços para reformar a religião a partir do seu interior (Menon, 1999). Essa mudança ocorreu simultaneamente com o processo de comunitarização e de politização da religião, evidenciado pelos diversos casos evocados acima, e que levou ao declínio da laicidade e aos ataques aos direitos das minorias. Quando esse tema se tornou central, a questão dos direitos das mulheres muçulmanas suscitou muito interesse, uma vez que era frequentemente associada ao Código do Estatuto Pessoal muçulmano e às reivindicações contraditórias sobre direitos humanos, identidade 
e gênero. Isso ficou muito evidente quando da controvérsia em torno do caso de Shah Bano.

O BJP é o mais ardente defensor de um Código Civil único, enquanto os conservadores muçulmanos estão entre seus oponentes mais ferozes. Em 1998, o BJP havia prometido promulgar um código único se chegasse ao poder. Até então, ele havia levantado essa questão principalmente para colocar o partido do Congresso em posição embaraçosa, uma vez que este último relutava em mudar o status quo devido à oposição muçulmana. O BJP alegou que não tocar nos direitos dos muçulmanos implicava em tratamento desigual e assimétrico. Isso serviu de justificativa à acusação de que a laicidade - e a prática laica em particular - equivalia a capitular aos muçulmanos por motivos eleitorais. Consequentemente, o partido denunciou uma desigualdade de tratamento no exercício do poder do Estado, uma vez que este último interveio para reformar o Código do Estatuto Pessoal hindu, sem fazer o mesmo em relação ao código muçulmano. De sua parte, os líderes muçulmanos temem que Ihes sejam impostas leis que levem inevitavelmente a práticas culturais uniformes e estranhas aos seus próprios costumes. Nesse contexto, as sobreposições e semelhanças entre pontos de vista hindus e muçulmanos são impressionantes. Ambos se esforçam para manter as hierarquias entre os sexos, preservando suas respectivas autoridade religiosa e autonomia (Sunder Rajan, 2003).

Durante muito tempo, o problema do Código Civil único (em nome, acima de tudo, da integridade nacional) raramente havia aparecido como uma reivindicação feminista nos debates públicos (Menon, 1999). Foi somente no contexto do novo Estado-nação que ele engendrou um debate opondo uniformidade e direitos das minorias, laicidade e leis religiosas, modernização e tradição (Sunder Rajan, 2003). Esse debate tomou um rumo mais complexo nos últimos anos, com a mudança de posição dos grupos de mulheres e as profundas divisões que despontaram entre elas sobre uma série de questões (Hasan, 2000). Uma mudança decisiva teve lugar com o conflito de Ayodhya e o crescimento espetacular do BJP e, paralelamente, com o temor cada vez maior dos muçulmanos de que Ihes fosse imposto um código "hindu". As feministas são unânimes em afirmar que todas as leis religiosas no tocante à pessoa são discrimina- 
tórias e devem, portanto, ser modificadas. No entanto, existem discordâncias quanto aos meios para alcançar isso - através de um Código Civil dependente do Estado ou de uma reforma interna da religião. Cientes de que a mudança jurídica estava intimamente ligada aos conflitos políticos e às diretrizes da maioria, os grupos de mulheres se esforçaram para dissociar as posições feministas da exigência de um Código Civil único, invocado pela direita hindu (Agnes, 1995). O movimento de mulheres evoluiu, desde então, para uma posição mais nuançada, que combina a ideia de uma reforma interna dos códigos de estatuto pessoal com a formulação de leis justas, em termos de gênero, derivadas do conceito do Código Civil Comum. Kumkum Sangari, por exemplo, aponta que a oposição entre o Código Civil único e as leis pessoais é "maniqueísta e politicamente peremptória".

A igualdade entre os sexos, de direitos democráticos e de pleno acesso a leis equitativas são impensáveis sem mudar os termos do debate. A questão não é saber se as mulheres deveriam estar sob a competência patriarcal do Estado ou da comunidade. Tal formulação não leva em consideração as reivindicações feministas. A questão não pode ser o Estado ou comunidade, mas sim a justiça entre os sexos enquanto princípio e perspectiva social (Sangari, 1995).

A mudança mais explícita diz respeito à associação de esquerda All India Democratic Women's Association (AIDWA), que até recentemente defendia o princípio de um único Código Civil e que hoje se pronuncia a favor da modificação gradual dos códigos de estatuto pessoal, dada a dificuldade de impulsionar a mudança apoiando-se na iniciativa do Estado. Essa organização é favorável a uma estratégia de ação sobre duas frentes, que combina a promoção de leis igualitárias e a reforma dos códigos existentes. Ela participou ativamente da mobilização de mulheres muçulmanas apoiando iniciativas comunitárias para a reforma jurídica dos códigos de estatuto pessoal, exigindo ao mesmo tempo uma legislação compatível quanto aos bens matrimoniais e à custódia dos/as filhos/as.

No contexto do debate sobre um Código Civil único, uma das características marcantes, nos últimos anos, foi a emergência de ações 
de mulheres muçulmanas buscando promover os direitos das mulheres ao invés de concentrar toda a sua energia na questão da mudança das leis pessoais (Katakam, 2004). Enquanto cidadãs e como membros da minoria mais importante da Índia, elas enfrentam desafios imensos e estão sujeitas a múltiplas discriminações em áreas tais como educação, emprego e acesso a programas de assistência social. A situação das mulheres muçulmanas evidencia atrasos em três pontos essenciais: conhecimento (nível de alfabetização e número médio de anos de escolaridade), poder econômico (atividade de trabalho remunerado e renda), e autonomia (em termos de tomada de decisão e de mobilidade física) - sendo todos eles elementos decisivos, que caracterizam o seu estatuto inferior (Hasan, Menon, 2004).

Isso certamente não depende unicamente da religião ou dos costumes que ela impõe. No entanto, quando se trata de direitos das muçulmanas, enfatiza-se de modo desproporcional o código do estatuto pessoal enquanto fator impeditivo da sua autonomia. Os muçulmanos - homens e mulheres - continuam a ser definidos/as pela sua identidade de origem, e a convicção de que o estatuto das mulheres muçulmanas deve-se a certas características 'islâmicas' intrínsecas e imutáveis é, consequentemente, amplamente disseminada. Todos os debates tendem a se concentrar seja sobre a possibilidade de uma reforma a partir de dentro, isto é, no seio da comunidade, associada a sanções religiosas para manter uma identidade muçulmana; seja sobre a necessidade de transcender a comunidade e de por fim às discriminações sexuais inerentes ao código do estatuto pessoal, através da adoção de um Código Civil único aplicável a todos os cidadãos. Essa preocupação resultou no ocultamento dos problemas econômicos, políticos e sociais que regem a vida cotidiana das muçulmanas.

Ao mesmo tempo, o fato de que um grupo influente e conservador de homens muçulmanos tenha se apropriado das reivindicacões das muçulmanas constitui um desafio para a sua emancipação. Por isso, o recente surgimento de fóruns e de associações de mulheres muçulmanas representa um passo importante para renovar o debate público sobre os direitos das mulheres. A aliança de grupos de mulheres muçulmanas com o movimento das mulheres e, ao mesmo tempo, com 
os movimentos pró-laicidade, democracia e direitos humanos, também tem desempenhado um papel crucial na expansão da luta pelos direitos das mulheres. Dois grupos com base em Mumbai - Womens'Research and Action Group (Wrag) e Aawaz-e-Niswan - expressam importantes iniciativas que vão para além do estatuto pessoal para promover a igualdade de género (Sikand, 2005). Eles visam fornecer ajuda e apoio para as mulheres pobres, analfabetas e marginalizadas, tornando-as conscientes das desigualdades de gênero operantes na sociedade e da importância de conseguir superá-las. Seu engajamento na luta pela reforma jurídica decorre diretamente dessas atividades. Assim como outros grupos de mulheres, as muçulmanas se mobilizam em torno de uma série de questões, dentre as quais a educação, o emprego e as violências domésticas (Vatuk, 2008). Embora até o momento os seus esforços não tenham suscitado um movimento de envergadura em favor de uma reforma entre os muçulmanos, todos eles representam passos decisivos para a construção de um movimento baseado em direitos. Pela primeira vez, se está lidando com as premissas de um debate sério sobre a reforma social.

O projeto de reforma jurídica é particularmente complicado pelos problemas com os quais se defronta a comunidade muçulmana, que continua sendo uma minoria vulnerável na Índia. Recentemente, uma comissão sobre o estatuto da comunidade muçulmana, conhecida como Comitê Sachar, mostrou que seus membros são pobres, marginalizados e sub-representados nas instituições públicas ${ }^{6}$. No entanto, eles têm seu próprio código de estatuto pessoal e têm o direito de praticar suas leis sob a proteção do Estado. Para as muçulmanas, isso implica que a defesa dos seus interesses, enquanto mulheres, mantém-se sob controle estrito do discurso identitário. As negociações políticas sobre o código do estatuto pessoal invariavelmente favoreceram as vozes conservadoras entre os muçulmanos, em detrimento do ponto de vista

6 O Primeiro-ministro, Manmohan Singh, criou em 2005 um Comitê superior sobre a condição social, econômica e educacional da comunidade muçulmana na Índia. Presidido pelo juiz Rajender Sachar e encarregado de investigar a situação socioeconômica dos muçulmanos, esse comitê apresentou seu relatório ao Primeiro-ministro em novembro de 2006. Ele revelou que os muçulmanos estão sub-representados e constituem uma subclasse, da mesma forma que as castas inferiores hindus (Government of India, 2006). 
e dos direitos das mulheres. Aqueles que advogam pela reforma interna do código do estatuto pessoal, apresentada como a melhor estratégia para expandir os direitos das mulheres muçulmanas, ignoram o fato de que esse tipo de posição tende a cristalizar as identidades dentro das fronteiras religiosas: muito pouca atenção foi dada às múltiplas identidades transversais que diferenciam as mulheres muçulmanas umas das outras de acordo com a sua pertença de classe, língua ou região, entre outras. Ora, tal abordagem, implicitamente baseada na suposição de uma identidade muçulmana homogênea, não seria capaz de levar em conta os diferentes pontos de vista internos à comunidade. A reforma jurídica se afigura delicada porque o arcabouço moral e jurídico sobre o qual ela repousa é supostamente imutável. Ela é apresentada como uma questão essencial para todos os muçulmanos, na medida em que disso depende a sua identidade, por assim dizer.

$$
* * *
$$

Nos últimos cerca de vinte anos, a questão da religião tomou um rumo muito mais político na Índia, mas nem por isso pôs fim à laicidade. Embora o nacionalismo hindu tenha possibilitado ao BJP modificar a agenda política na década de 1990, ele não foi capaz até agora de desafiar os fundamentos do Estado laico ou de ampliar seu número de cadeiras de maneira decisiva. Na realidade, a direita hindu tem enfrentado sérios obstáculos estruturais e uma forte oposição de diversos grupos da população. O veredito final a favor de um governo laico em duas eleições parlamentares sucessivas (2004 e 2009) dá uma idéia da forte oposição à política religiosa e ao sectarismo. A persistência de um Estado laico numa sociedade profundamente religiosa e num contexto em que o nacionalismo étnico constitui uma força poderosa em escala mundial, e particularmente na Índia, é de máxima importância.

$\mathrm{Na}$ Índia, a política de identidade e a laicidade parecem andar de mãos dadas. O principal problema não é a escalada da política religiosa, mas a importância desmesurada atribuída à política identitária na vida pública, que dá origem a um duplo paradoxo. Em primeiro lugar, embora a Índia seja um Estado laico, os cidadãos comuns não têm mais acesso às 
instituições públicas senão através da sua identidade religiosa e social. Em segundo lugar, o apoio ao conservadorismo dos muçulmanos decorre de uma concepção de laicidade que admite a intervenção do Estado face à religião majoritária, mas não frente às religiões minoritárias - e isso, em nome da própria laicidade, paradoxalmente.

A direita hindu demonstrou uma grande capacidade de mobilizar as mulheres, mas não numa perspectiva progressista ou de emancipação, embora a sua participação nas campanhas possa contribuir para melhorar marginalmente a situação das mulheres donas de casa. Em diversas ocasiões, o BJP apoiou os direitos das mulheres, mas foi sempre para que elas apoiassem seu objetivo principal - tomar o poder. De modo geral, o militantismo das hindus oferece um exemplo notável do modo como o BJP e o Sangh Parivar instrumentalizaram as mulheres para alcançar seus objetivos políticos. Ao mesmo tempo, a resistência das comunidades minoritárias à reforma jurídica, em nome da preservação de sua identidade religiosa, representa um sério problema para a igualdade de gênero. Desse ponto de vista, o principal desafio diz respeito à ânsia do Estado em dar resposta à crescente influência de dirigentes conservadores, reforçando com isso a política identitária e as fileiras daqueles que se opõem aos direitos das mulheres. Embora os grupos de mulheres tenham se levantado firmemente contra a política religiosa e contra os patriarcados religiosos em todas as comunidades, os direitos das mulheres têm sido frequentemente marginalizados, devido precisamente à vulnerabilidade das minorias. As muçulmanas, muitas vezes empurradas para a ala conservadora da comunidade, pagaram um alto preço por esse compromisso. A ironia da laicidade na Índia é que a proteção da diversidade e dos direitos das minorias resultou num movimento de recuo em direção ao conservadorismo.

\section{REFERÊNCIAS}

AGNES, Flavia. Hindu Men, Monogamy and Uniform Civil Code. Economic and Political Weekly, vol. 30, $\mathrm{n}^{\circ}$ 50, 1995.

BASU, Amrita (1998). Hindu Women's Activism in India and the Question it Raises. In BASU, Amrita; JEFFERY Patricia (Eds.). Appropriating Gender: Women's Activism and Politicized Religion in South Asia. New-York \& London: Routledge, 1998. 
BASU, Amrita. The Dialectics of Hindu Nationalism. In: KOHLI, Atul (Ed.). The Success of India's Democracy. Cambridge: Cambridge University Press, 2001.

BASU, Amrita. Women, Political Parties and Social Movements in South Asia. UNRISD, Paper ocasional, 5 de Julho, 2005.

BEDI, Tarini. Feminist Theory and the Right-Wing: Shiv Sena Women Mobilize Mumbai. Journal of International Women's Studies, vol. 7, n 4, Maio, 2006.

BHARGAVA, Rajeev. The Political Psychology of Hindu Nationalism. Open Democracy, 5 Novembro, 2003.

BHARGAVA, Rajeev. The Distinctiveness of Indian Secularism. 2007. Disponível em: $<$ Www.yale.edu/macmillan/southasia/events/bhargava.pdf>.

CHATTERJEE, Partha. Secularism and Tolerance. In: BHARGAVA, Rajeev (Ed.). Secularism and its Critics. Delhi \& New York: Oxford University Press, 1998.

GOVERNMENT OF INDIA. Social, Economic and Educational Status of the Muslim Community of India. Comitê de Alto Nível do Primeiro-Ministro, Secretaria do Gabinete, New Delhi, 2006.

HASAN, Zoya. Minority Identity, State Policy and the Political Process. In: HASAN, Zoya (Ed.). Forging Identities: Gender, Communities and the State in India. Delhi: Kali for Women, 1998.

HASAN, Zoya. Uniform Civil Code and Gender Justice in India. In: DE SOUZA, Peter Ronald (Ed.). Contemporary India: Transitions. New Delhi \& Thousand Oaks: Sage, 2000. HASAN, Zoya; MENON, Ritu. Unequal Citizens: A Study of Muslim Women in India. Delhi: Oxford University Press, 2004.

KATAKAM, Anupama. The Divorce Debate. Frontline, vol. 21, $\mathrm{n}^{\circ} 18,28$ de Agosto-10 de Setembro, 2004.

MEHTA, Pratap Bhanu. Reason, Tradition and Authority: Religion and the Indian State. In CREPPELL, Ingrid; HARDIN, Russel, MACEDO, Stephen (Eds.). Toleration on Trial. Lanham: Lexington Books, 2008.

MENON, Nivedita. Introduction. In: MENON, Nivedita (Ed.). Gender and Politics in India. New Delhi \& New York: Oxford University Press, 1999.

NEEDHAM, Anuradha, SUNDER RAJAN, Rajeswari (Eds.). The Crisis of Secularism in India. Delhi: Permanent Black, 2007.

PARASHAR, Archana. Women and Family Law Reform in India: Uniform Civil Code and Gender Equality. Delhi: Sage, 1992.

PRAKASH, Gyan. Secular Nationalism, Hindutva and the Minority. In NEEDHAM, Anuradha, SUNDER RAJAN, Rajeswari (Eds.). The Crisis of Secularism in India. Delhi: Permanent Black, 2007. 
SANGARI Kumkum. Politics of Diversity. Religious Communities and Multiple Patriarchies. Economic and Political Weekly, vol. 30, n 52, Dezembro, 1995.

SARKAR, Tanika. Woman, Community and Nation. A Historical Trajectory for Hindu Identity Politics. In: BASU, Amrita; JEFFERY, Patricia (Eds.). Appropriating Gender: Women's Activism and Politicized Religion in South Asia. New-York \& London: Routledge, 1998.

SARKAR, Tanika (1999). The Gender Predicament of the Hindu Right. In: PANIKKAR, K. N. (Ed.). The Concerned India's Guide to Communalism. Delhi: Viking, 1999.

SHANI, Ornit. Communalism, Caste and Hindu Nationalism: The Violence in Gujarat. Cambridge: Cambridge University Press, 2007.

SIKAND, Yoginder. The Muslim Personal Law Debate: Need to Listen to Alternative Voices. Disponível em: <www.islaminterfaith.org>. 5 de Maio, 2005.

SOM, Reba. Jawaharlal Nehru and the Hindu Code: A Victory of Symbol over Substance. Modern Asian Studies, vol. 28, n 61, 1994.

SUNDER RAJAN, Rajeswari. The Scandal of the State: Women, Law, and Citizenship in Post-colonial India. Delhi: Permanent Black, 2003.

VATUK, Sylvia. Islamic Feminism in India: Indian Muslim Women Activists and the Reform of Muslim Personal Law. Modern Asian Studies, vol. 42, n²-3, Outubro, 2008. 